\title{
Radial Probe Endobronchial Ultrasound
}

National Cancer Institute

\section{Source}

National Cancer Institute. Radial Probe Endobronchial Ultrasound. NCI Thesaurus. Code C150569.

Endobronchial ultrasound that employs a flexible catheter housing a rotating ultrasound transducer to produces a 360 degree (radial) ultrasound image. 